Chapter 19

\title{
Adsorption in Extracorporeal Blood \\ Purification: How to Enhance Solutes Removal Beyond Diffusion and Convection
}

\author{
Fabio Grandi, Piergiorgio Bolasco, \\ Giuseppe Palladino, Luisa Sereni, \\ Marialuisa Caiazzo, Mauro Atti and \\ Paolo Maria Ghezzi \\ Additional information is available at the end of the chapter \\ http://dx.doi.org/10.5772/52272
}

\section{Introduction}

Uremic syndrome is linked to a plethora of uremic toxins circulating in the body in ESRD patients. Their overall spectrum is partly or entirely unexplored despite the need to urgently define the specimens and the patho-physiology beyond their high blood levels to address new or more selective removal strategies.

It is generally accepted that convective hemodialysis is the best choice to remove large part of the molecular spectrum, even though it is not fully demonstrated its superiority in terms of clinical outcomes. Then, transport mechanisms can benefit from maximizing all the physico-chemical principles including diffusion for small solutes, convection for middle molecules and adsorption for large molecular size uremic toxins. The latter has not been fully adopted in hemodialysis and this transport mechanisms is limited to the intrinsic capability of dialysis membrane to adsorb macromolecules while transporting solutes by diffusion and/or convection. However, poorly has been explored about the use of sorbents to enhance the solute removal in hemodialysis.

The purpose of this chapter is to summarize the main contributions of so far published clinical and technical experiences.

The chapter will be structured as follow: first we introduced a summary of the basic principles of solutes transport and relative contribution of the different mechanisms to the overall 
solutes removal; then, we described the extracorporeal techniques using adsorption as further transport mechanism; third we introduced the filtration adsorption architecture and we described the proteomic profile in extracorporeal adsorption hemodialysis; finally we reviewed the main clinical experiences with two techniques, the hemofiltration reinfusion (HFR) and coupled plasma-filtration adsorption (CPFA).

\section{Some basic principle of solutes transport through a semipermeable membrane and relative contribution of the different mechanisms to the overall clearance}

Main purposes of extracorporeal blood purification treatments are the elimination of toxins from the body and in the presence of renal failure (acute or chronic), the recover of the hydro-electrolytic and acid-base homeostasis. Beyond this direct aims, the extracorporeal treatments can also help, particularly in chronic diseases, to recover the anaemic, the nutritional status and to control the inflammatory body response. Extracorporeal blood purification treatments refer usually to three major techniques: hemodialysis (HD), hemofiltration (HF) and hemodiafiltration (HDF) which can be delivered as intermittent therapiesor continuous ones.

Mass transfer through a semipermeable membrane are governed by three major mechanisms: diffusion (described by Fick's law); convection (described by the Staverman law, solvent drag principle driven by the hydrostatic pressure drop); adsorption (which refers to the separation of a solute from a mixture by binding the specimen to a sorbent surface).

Usually, all the three mechanisms occur simultaneously through a semipermeable membrane but the relative contribution of each transport mechanism is given by the chemicalphysical properties of the media respect to the specific solute (diffusivity, hydraulic permeability and solute affinity), and the driving forces (concentration gradient, hydrostatic pressure gradient). Then, depending on the specific membrane characteristics and operating conditions we can have only diffusive transport (HD) with negligible effect form convection and adsorption, only convection (HF, without any contribution from diffusion and negligible from adsorption), only adsorption (hemoperfusion - HP) or a combination of those.

In HD, a hydrosoluble solute movement through two phases is driven by its concentration gradient, but it is partially limited by the diffusive permeability, sieving coefficient and membrane cut-off in relation to its molecular weight and geometry. Then, the mass flow is usually high for low molecular weight, like urea and poor for middle-high molecular weight solutes, like $\beta 2$-microglobulin.

In HF, a hydrosoluble solute movement is driven by the hydrostatic pressure gradient but it is limited by the hydraulic permeability of the membrane, the sieving coefficient and the membrane cut-off. The clearance and mass transfer are equal to ultrafiltration ( $u f$ ) flow which is limited by the blood flow rate, hematocrit (Hct), total protein content. As a consequence middle-high molecular weight toxin are easier removed than in the only diffusive 
case, while small molecular weight toxins do not take so much benefit from the convective transport.

Adsorption, especially of proteins, always occur onto the inner surface of the membrane and inside the porous frame along the membrane wall. This phenomenon has two major implications during extracorporeal treatment: 1) it allows for mediating the hemocompatibility of the artificial surface and its thrombogenicity; 2) the adsorbed protein layer can significantly interfere with both diffusion and convection. Adsorption can be advocated as further removal mechanisms especially for low molecular weight protein, like $\beta 2$-microglobulin, inflammatory mediators, like endotoxin fragment, IL-1 and IL-6, and in some extent also large molecular weight protein like immunoglobulin G [1].

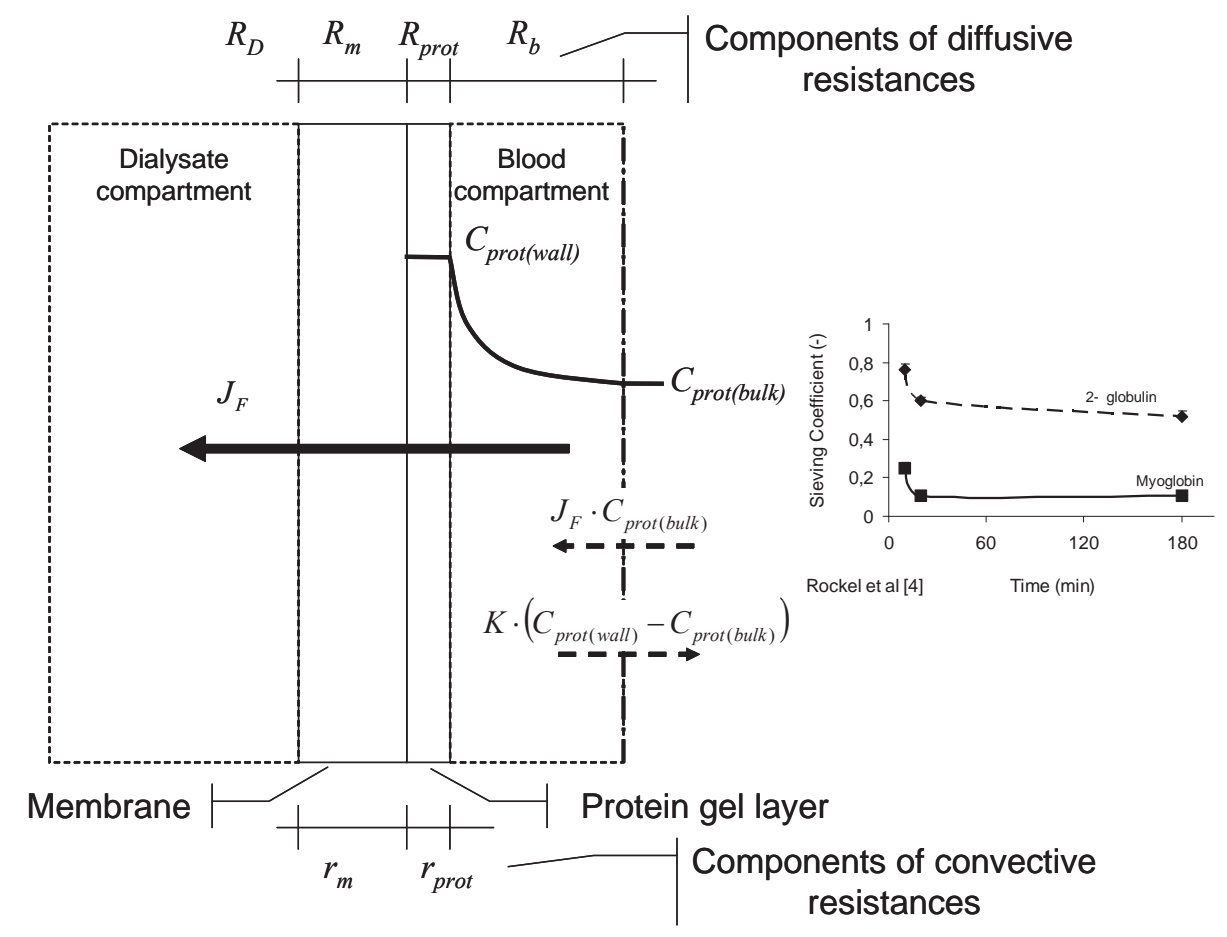

Figure 1. Major determinants of diffusive an convective transport behaviour through a semi permeable membrane. Legend of the figure: $J_{F}=$ water flow rate, $K=$ free diffusion coefficient, $C$ protein concentration at wall or at the centre of the fiber.

In normal operating conditions it exists an interference among these three transport mechanisms. Indeed, convective solute removal can be heavily influenced by the membrane fouling or gelling and concentration polarization. Fouling refers to the formation of a protein layer onto the inner surface of the membrane which has been shown to significantly decrease the sieving coefficient of the membrane [2]. Concentration polarization indeed con- 
sists of a second protein layer which is a function of theamount of protein delivered to the inner membrane surface by convective flow, and the amount of protein back diffusing from this high protein concentration boundary layer to the inner bulk phase of plasma at the center of the fiber (Figure 1). Again, the concentration polarization constitutes a barrier to solute movement toward the membrane surface decreasing both resistances to solute transport through the media and the overall sieving coefficient. In fact, the sieving membrane coefficient can be thought composed as: 1 ) intrinsic sieving coefficient $\left(s_{i}=C_{d} / C_{\text {wall }}\right)$, (where $C_{d}$ is the solute concentration in the dialysate and $C_{\text {wall }}$ is the solute concentration at the membrane wall) which is inherent to the membrane characteristic and solute and 2) the observed sieving coefficient $\left(S=C_{d} / C_{b u l k}\right)$, (where $C_{b u l k}$ is the solute concentration at the center of fiber) which is also influenced by fouling and polarization [3].

In vitro data indicate that both hydraulic permeability and middle-high molecular weight solute sieving coefficient fall down during convection with high permeable membranes. Rockel et al [4] showed that middle-high molecular weight molecules decrease the sieving coefficient during the first minutes of dialysis with synthetic Polysulfone membranes. The extent of reduction was by $21 \%$ after $20 \mathrm{~min}$ and $32 \%$ after $180 \mathrm{~min}$ from the peak value of the sieving coefficient of 0.76 at $10 \mathrm{~min}$ for $\beta 2$-microglobulin. Even more was the reduction of $S$ for myoglobin which achieved $-56 \%$ just after the firs 20 min of treatment.

Finally, fouling and concentration polarization also influences diffusion and convection by changing or introducing some further flow resistance components to the intrinsic characteristic membrane resistances (Figure 1).

Hemodiafiltration was initially proposed as a mixed technique that offered the advantages of two systems of transmembrane transport: diffusion and convection. This combination allowed better removal both middle molecules, particularly with respect to HD, and small uremic toxins when compared to $\operatorname{HF}[5,6]$.

Although HDF is characterized by processes that can negatively interfere between diffusion and convection, leading to academic and clinical arguments over the choice between pre-, post- or pre/post dilution, overall the development of HDF offers, without doubt, an important positive evolution in dialytic strategy. Beyond the convection diffusion interference HDF is objectively associated with further two issues: a) quantity and quality of the reinfusion fluid; b) loss of important physiologic components in the $u f$. In fact, the choice of the $Q_{u f}$ rate depends on several factors; first, from a practical point of view, the $Q_{u f}$ must always be considered within the limits permitted by the blood flow $\left(Q_{b}\right)$, Hct, total protein determining factors of fractional filtration. Elevated $Q_{u f}$ improves the depurative efficiency of the treatment, but it also necessitates large quantities of reinfusion solution that must absolutely have a guarantee of safety for the patient. The utilization of ready-to-use reinfusion bags produced by the pharmaceutical industry are associated with notable problems including handling (repeated connections to the hematic lines, storage) and cost. This has led to interest in on-line production of reinfusion fluids that can guarantee sterility and allow elevated $Q_{u f t}$ thus leading to economic and practical handling issues to give a good cost/benefit ratio. Furthermore, high $Q_{u f}$ can often lead to severe depletion of substances such as vitamins, essential and branch chain amino acids (aa), as far as the albumin. Chronic renal failure patients 
often have high nutritional losses during both convective and diffusive dialytic treatments that may be closely linked to other patient comorbidities or that may aggravate patient health and well being. HDF, in particular, is associated with remarkable losses of amino acids and it is not surprising that higher losses are found with higher hydraulic permeability membranes [7].

As far the interference between convection and diffusion is of concerned, convective clearance (and therefore mass transfer) of a diffusible solute in HDF can not be fully represented by the $u f$ flow $\left(Q_{u f}\right)$, in that the simultaneous process of both convection and diffusion diminish the solute's concentration.

The overall interferences can be simply accounted knowing the overall dialyzer clearance as a function of operating condition $\left(Q_{b}, Q_{u f}\right)$ and overall mass transfer coefficient-area $(K o A)$. Assuming the same approach described by Sargent and Gotch [8] the overall dialyzer clearance, $K_{T}$, is:

$$
K_{T}=K_{d}\left(1-\frac{S \cdot Q_{u f}}{Q_{b}}\right)+S \cdot Q_{u f}
$$

Where $K_{d}, S, Q_{u f}$ and $Q_{b}$ represent respectively the diffusive clearance, the sieving coefficient, the ultrafiltration rate and blood flow rate.

In turn, $K_{d}$ can be expressed as a function of the membrane characteristics, and operative condition of the dialyzer, as follow [9]:

$$
K d=Q_{b} \cdot \frac{e^{\left[\frac{K o A}{Q_{b}} \cdot\left(1-Q_{b} / Q_{b}\right)\right]}}{e^{\left[\frac{K o A}{Q_{b}}\left(1-Q_{b} / Q_{d}\right)\right]}-\frac{Q_{b}}{Q_{d}}}
$$

Where $K o A$ is the overall mass transfer coefficient per surface area $\left(K o A=1 / \sum_{i} R_{i}\right)$ and $Q_{d}$ the dialysate flow rate. The mass transfer coefficient is a function of the transmittance (inverse of the overall resistance $R$ ). From the equations above it can been simply accounted what is the $K_{T}$ change for variations of $K o A$ up to $-50 \%$ and of $Q_{u f}$ in the allowed range for a given $Q_{b}$ (maximum $30 \%$ ).

The overall clearance is plotted in Figure 2 as a function of $Q_{u f}$ and $K o A$ for two solutes like urea and vitamin B12 (molecular weight of 60 and 1355 Da, respectively), often used as markers to characterize the dialyzer performances. Values are shown as percentage respect to the nominal value of $K_{d}$. It is worth to note that $K_{T}$ does not change linearly with $Q_{u f}$ but it is proportional to its change with a slope $<1$. Moreover the change is much more marked for middle-high molecular weight solutes. In fact, in absence of $\mathrm{KoA}$ variations the urea $K_{T}$ in- 
creases up to $+3 \%$ with $Q_{u f}$, while in presence of high $K o A$ impairment when no convection is applied $\left(Q_{u f}=0\right)$ the $K_{T}$ decreases to $-15 \%$. The Vitamin B12 $K_{T}$ increases linearly with $Q_{u f}$ up to $+16 \%$ in absence of $K o A$ variations but decreases by $-30 \%$ in case of $K o A$ impairment in absence of convection. Nonetheless, when convection and fouling occur simultaneously, the positive contribution from convection itself, can be even knock down by KoA impairment and at higher $Q_{u f}$ one should expect higher $K o A$ changes especially for high molecular weight solutes. This observation is in line with the results by Rockel [4] who found that protein adsorption has a negligible impact on membrane characteristic of polysulphone membrane for low molecular weight solutes while it significantly alters the sieving coefficient of molecular weight substances above 11'000 Da.
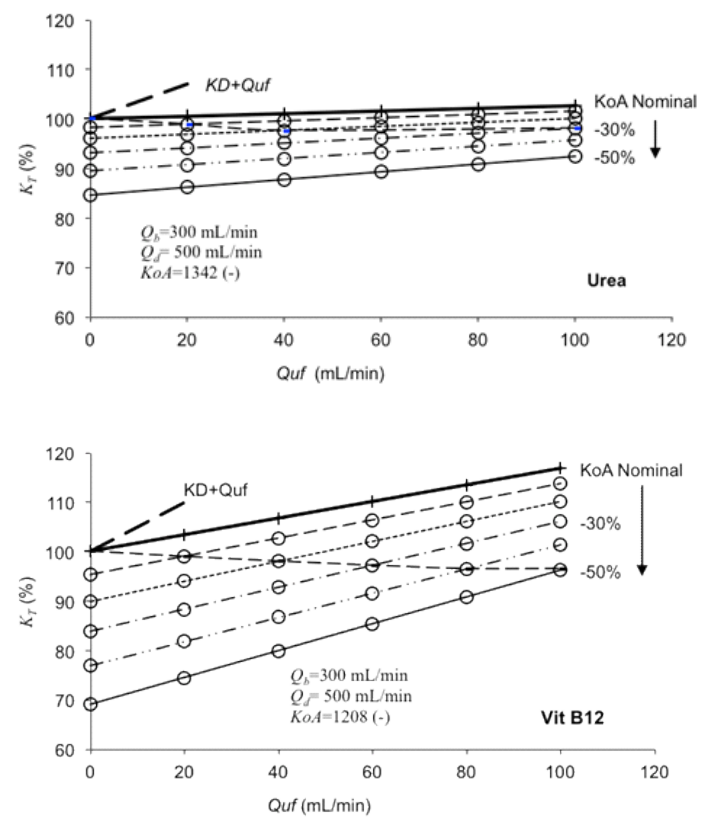

Figure 2. Relationship between $K_{T}$ and changes of $Q_{u f}$ and $K o A$.

Then according to these results, it is almost evident that less interference among the transport mechanisms should lead to better $K_{T}$. Maximum transport mechanisms can be achieved when they take place separately even though not all the interference like fouling and concentration polarization can be avoided at all but only minimized.

To solve this problem, Ghezzi et al [10] proposed a novel form of HDF that used a twin stage filter, in series, to separate diffusion from convection. The two stages permitted simultaneous convection and diffusion but also offered several benefits over traditional HDF combined in one filter unit. The first stage of the filter used a membrane with high hydraulic permeability for convective solute removal, while the second stage used a membrane with 
low hydraulic permeability for diffusive solute removal and to control the patient weight. Reinfusion of substitution fluids prepared on-line or in bags occurred between the two filter stages.This fluid was equal to the $Q_{u f}$ in order to maintain the effective $Q_{b}$. Therefore, this technique physically separates convection from diffusion, thus leading to two main results: a) the continuous availability of pure $u f$ during the whole duration of the session; $b$ ) the absence of dialysate backfiltration. The method was called Paired Filtration Dialysis (PFD) [figure 3], and his efficiency and tolerance have been proven [11].

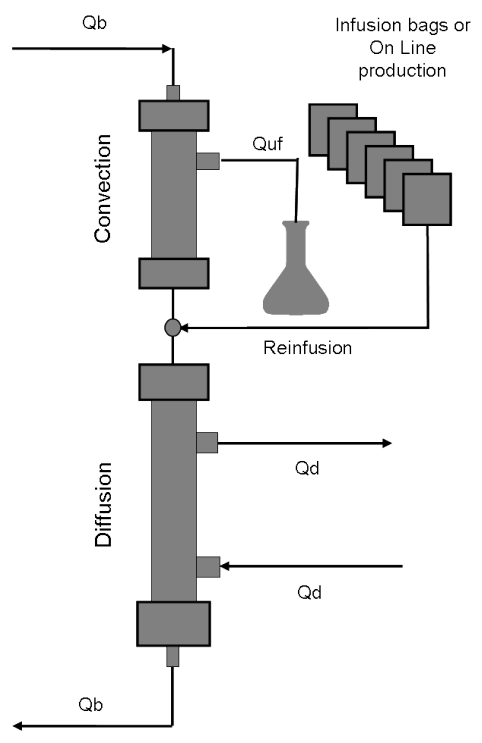

Figure 3. Paired Filtration Dialysis (PFD).

\section{Extracorporeal techniques using adsorption}

According to the "Consensus Conference on Biocompatibility," [12] adsorption is a method for removal of molecules from blood or plasma by molecules attachment to a surface incorporated in a device within an extracorporeal circuit. Sorbents are substances that, because of their physical and chemical characteristics, adsorb on their surface other elements in solution. In medicine, sorbents have been used to rapidly eliminate both industrial and pharmacological toxins, as well as some endogenous toxins such as bilirubin or porphyrines. They can be divided in two large categories: (1) those that have hydrophobic properties and therefore adsorb the molecules present in the solution in contact with the sorbent, and (2) those that eliminate solutes by chemical affinity [13]. Within the first category, hydrophobic sorbents, there are two subgroups: charcoal and non-ionic macroporous resin. 
Charcoal is produced both from biological substances, such as coconut shells or peach pits and from non-biological substances, such as petroleum. The charcoal is activated by controlled oxidation in air (carbon dioxide) or steam. Adsorption into charcoal occurs through its pores, and therefore, its efficiency depends on the total number of pores and their radius. The charcoal may be coated or uncoated. Coating charcoal reduces some of its adverse effects, such as platelets entrapment, but it also reduces its efficiency, since the diffusion of the toxin from the blood to the charcoal is limited by the thickness of the polymer membrane, which covers it. The non-ionic macroporous resins are very similar to charcoal and are micro-sphere agglomerates, which adsorb the toxins they eliminate in their surface. Styrene-divinylbenzene polymers are generally used in clinical practice. The sorbents, which eliminate substances by chemical affinity, are fundamentally ion exchange resins, which exchange one ion for another of the same electrical charge. Some substances, which act by chemical links between the sorbent and the solute, are also considered "chemi-sorbents."

The use of sorbents in clinic can be divided in two big categories: hemoperfusion (HP) and plasma or $u f$ perfusion.

Hemoperfusion is the passage of blood across material that adsorbs various solutes or substances [12]. In nephrology, sorbents were first used by Muirhead and Reid in 1948 [14] and later by Yatzidis in 1964 [15] in HP to eliminate uremic toxins. However, the adverse effects, principally platelets depletion, hemolysis, hemorrhage, and hypotension, outweighed the advantages. Although the majority of these adverse effects were solved thanks to the introduction of coated charcoal by Chang in 1966 [16, 17], the isolated use of HP for the treatment of uremia has been discontinued. At present, the use of HP is an accepted treatment for certain exogenous intoxication (pharmacological or suicidal).

After the abandonment of HP alone in the treatment of chronic renal failure, sorbents were used in combination and simultaneously with other dialysis methods. Gordon et al in 1969 [18] first described a HD technique in which the blood system, including the dialyser, was the usual one, but only six litres of dialysis fluid were used in the entire session, as the dialysate was regenerated by sorbents. The cartridge containing the sorbents consisted of four compartments: the first with urease, which transformed urea into ammonia; the second with zirconium phosphate, which eliminated ammonia, potassium, calcium, and magnesium; the third compartment, containing hydrated zirconium oxide, which eliminated phosphates; and the final compartment using charcoal, which eliminated a large number of both small and middle molecules. The system, called "Redy ${ }^{\circledR}$," had the advantage of not needing running water nor any type of special installation and, therefore, could be quickly operated anywhere, for example, intensive care units and catastrophe sites, such as earthquakes. It also had various disadvantages, like unbalance of the sodium and acid-base equilibrium, but the most important was the release of aluminium to the dialysis fluid [19].

Another possibility of combining sorbents with HD was the inclusion of these substances in the dialyser membrane [20]. In this way, the patients blood was purified by diffusion as well as by adsorption on passing through the dialyser. The disadvantage to this method was its short efficiency period, as the sorbent became saturated in the first hour of dialysis and then stopped eliminating the uremic toxins. The Redy ${ }^{\circledR}$ sorbent cartridge was used by Shaldon et 
al [21] to regenerate the ultrafiltrate for reinfusion. This study was discontinued because of the appearance of osteomalacia in the patients [22].

\section{Filtration adsorption architecture}

The easy availability of isolated continuous $u f$ during PFD led to the hypothesis that it could be "regenerated" and used as an endogenous reinfusion fluid. In 1992 [23] the first attempt to regenerate the $u f$ was done with $130 \mathrm{~mL}$ of non-coated mineral carbon sorbent along the uf stream. The method was called Hemo Filtrate Reinfusion (HFR) and it is illustrated in Figure 4. HFR is a renal replacement therapy that utilizes convection, diffusion and adsorption. It uses a double stage filter that consists of a high permeability filter in the first convective stage and a low flux filter in the second diffusive stage.

The stages of the filter allow complete separation of convection from diffusion. The convective part of the first stage allows pure $u$ f to flow through a sorbent resin cartridge. The potential of non-coated carbon sorbent to activate the contact phase [24,25], lead to switch the carbon cartridge to a hydrophobic styrenicdivinylbenzene resin $(40 \mathrm{~mL})$. This has the potential advantage of a high affinity for several uremic toxins and middle molecules such as $\beta 2$-microglobulin, homocystein, angiogenin, PTH, and several chemokines and cytokines [26, 27].

The resin structure allows molecules to flow through many pores and channels enlarging the sorbent surface area up to approximately $700 \mathrm{~m}^{2} /$ gram. Despite its high affinity for many different uremic toxins, the resin has been proven not to [28] retain albumin and essential physiological molecules. Toxins are adsorbed to the resin beds and the purified $u f$ is then reinfused between the first and second stage of the filter. The first convective/adsorption stage has no net fluid removal. The blood and reinfused regenerated uf then undergo traditional dialysis. The second stage works as conventional HD which also includes the patient net fluid loss.

Reasons to clear plasma water instead of whole blood are: a) a lower plasma water flow rate than the blood flow and consequently longer contact time with the resin and higher toxin adsorption; b) low sequestration of coagulative factors improving the hemocompatibility; c) absence of any depletion of inflammatory cells and platelets. The technique proved easy to use and offered high treatment tolerance, an optimal balance of bicarbonate (since it is not adsorbed and therefore it is reinfused) and was also associated with diminished inflammatory response often related to the exogenous reinfusion. Urea, creatinine, uric acid, $\mathrm{Na}^{+}, \mathrm{K}^{+}$, phosphates and bicarbonates are not adsorbed and remain unchanged after flowing through the cartridge. These can be managed during the second stage of the diffusive stage of the circuit. Thus the regenerated $u f$ in the closed circuit is an endogenous reinfusion of patient plasmatic water. In particular, HFR has been associated with an aa loss similar to that observed with low flux HD, and surely much lower than other high flux HD or HDF on average as high as 33\% [29]. The amino acids loss during HFR and low flux HD is approximately $10-11 \%$.

The $u f$ is much more than merely plasma water containing a few uremic toxins. Studies using proteomics and other chromatographic analyses have shown that $u f$ contains between 
over 18,000 proteins and peptides [30-32]. Richter et al [30] found that $u f$, analyzed by MALDI-TOF mass spectrometry, consisted of approximately: $95 \%$ masses that were smaller than $15 \mathrm{kDa} ; 55 \%$ of the masses were found to be fragments from plasma protein (fibrinogen, albumin, $\beta 2$-microglobulin, cystatin); $7 \%$ were hormones, growth factors and cytokines; $33 \%$ consisted of complement, enzymes, enzyme-inhibitors and transport proteins. Weissinger et al. [32] also found a wide polypeptide's spectrum in a recent study that analyzed $u f$ from uremic patients using either high or low flux hemodialyzer. In this study they found a higher number of polypetides in samples obtained from uremic patients with high flux dialyzers compared to low flux dialyzers (1394 polypeptides with high flux ones vs. 1046 with low flux dialyzers), as well as a significant differences when they used healthy donors $u f$ by filtering plasma with a $5 \mathrm{kDa}$ or $50 \mathrm{kDa}$ cut-off membranes (590 polypeptides for the high cut off, 490 polypeptides for the low cut off).

Although the study focused on characterization of uremic toxins, there are certainly a lot of beneficial substances that are also lost during HDF with high convection. In conclusion, peculiar characteristic of HFR over classical HDF, is that the technique allows a better removal of high molecular weight toxins, and the reinfusion of vitamins, hormones and other physiologic compounds.

The cartridge adsorption was optimized progressively as investigated by different studies, to determine the maximal adsorption at different $u f$ flow rates for different cartridge diameters and quantities of resin. The treatment is performed on the Formula Plus ${ }^{\mathrm{TM}}$ dialysis machine (Bellco, Mirandola, Italy) which is equipped with a dedicated algorithm which automatically determines the best Quf based initially on the maximal linear velocity (the flow rate that gives the best adsorption). The machine also determines the patient's Hct and transmembrane pressure to adjust the Quf based on these parameters.Thus the $Q u f$ is usually higher at the start of the treatment and then adjusts if necessary to reduce the flow rate based on changes in hemoconcentration [33]. For the handling point of view, this therapy does not add much more respect to an on-line hemodiafiltration, since it adds an external cartridge to be connected along the reinfusion pathway. The remaining extracorporeal circuit is fully preassembled and do not introduce any extra work for the nurses. On the contrary, the advantage of endogenous reinfusion relies in the reduction of extra costs and extra work associated to the analysis of the on-line substitution fluids and to the need of devices and preventive maintenance to guarantee the fluid purity. Finally, the complexity of intrasession management is located inside the dialysis machine being the $Q_{u f}$ automatically adjusted according to the operative conditions in terms of pressures and flow. This tool, again, reduces the complexity of manual adjustment of ultrafiltration rate which must cope with the intra-session changing trans-membrane pressure developed in the hemodialyzer in conventional on-line hemodiafiltration. Very often, this aspect represents one of the major limitations to achieve high exchange volumes OL-HDF.

The HFR architecture has been next extended in terms of plasma water solutes selectivity and sorbent capacity. In fact, the use of more permeable membranes, in the convective chamber, with higher cut-off allows for high molecular weight solute to flow through the sorbent. 
In chronic dialyzed patients in order to reduce the effect of high molecular weight toxins retention, the micro-inflammation and the malnutrition status it is necessary remove molecule with high molecular weight over the albumin limit. For this purpose, the evolution of the HFR technique in SUPRA HFR (by the use of new super high cut-off membrane in the convective chamber: Synclear 0,2 with albumin sieving in water of 0.2 ), has allowed to achieve this purpose without loss of albumin. This is possible because the resin contained in the cartridge doesn't adsorb the albumin and therefore re-infuse that to the patient [28].

End stage renal disease patient is not the only one that could take advantage of the filtration and adsorption mechanism. Septic shock patients with or without Acute Kidney Injury (AKI) require the removal of high molecular weight inflammation mediators (like, IL-1 $\beta$, IL-6, IL-8, IL-10, Macrophage Inflammatory Protein- $\alpha$ and $\beta$, TNF- $\alpha$ ) which cannot be achieved with only ultrafiltrate flowing through the sorbent resin $[34,35,66,67]$.
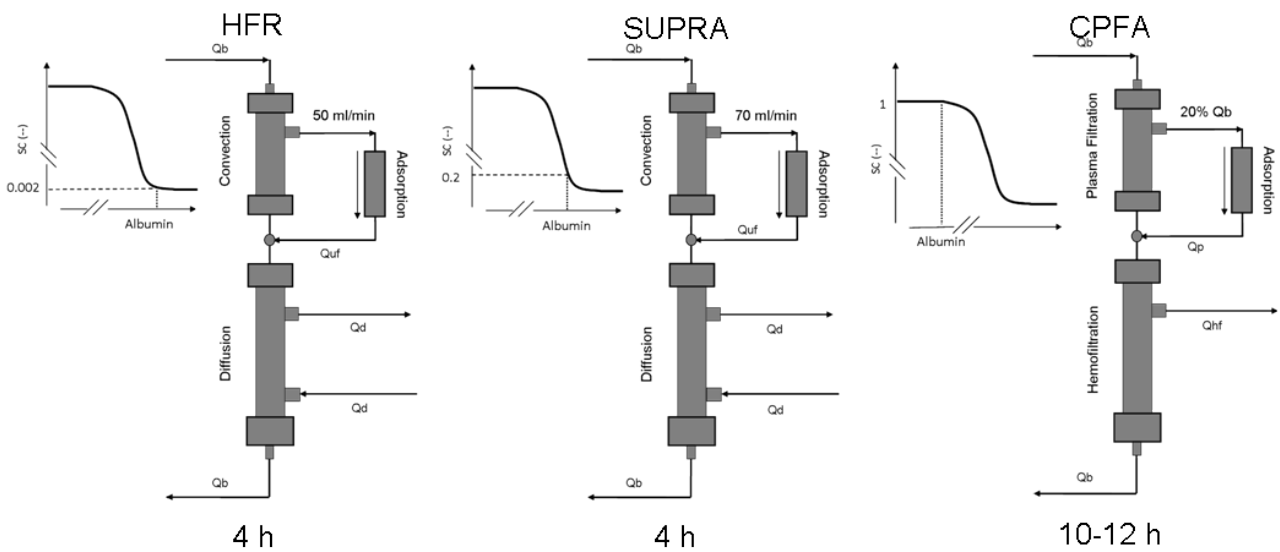

Figure 4. The Filtration Adsorption architecture, form left to right: standard HFR, super high-flux HFR (SUPRA) and CPFA. Figure shows also the albumin sieving coefficient o each convective chamber, the typical uf or plasma flow rate and the length of each session.

For this purpose a special technique, dedicate to this kind of patients, that couple plasma filtration with adsorption have been parallelly developed. The name of this technique is Coupled Plasma Filtration Adsorption (CPFA) [36].

The first stage is now a plasma filter (MICROPES $0.45 \mathrm{~m}^{2}$ polyethersulfone which separates the corpuscular part of the blood from plasma) replacing the convective membrane. Obviously, the fluids treated are very different from those in HFR and then they required to develop a new cartridges with high sorbent properties and performances. Then, a nonselective hydrophobic styrene resin cartridge with macroporous structure $50^{\prime} 000 \mathrm{~m}^{2} /$ cartridge is used. Finally, a synthetic, high-permeability, $1.4 \mathrm{~m}^{2}$ polyethersulfone hemofilter clears the reconstituted blood in a post-dilution mode to restore the hydro-electrolytic and acid-base bal- 
ance and the removal of small molecular weight toxins. The outline of the development of this architecture is shown in Figure 4.

The post-dilution re-infusion rate can be set for up to a maximum of 4 liters $/ \mathrm{h}$. The blood flow is usually $150-180 \mathrm{ml} / \mathrm{min}$ while the plasma filtration rate is maintained at a fractional filtration of the blood flow (approximately 15-20\%).

The treatment is performed for a $10 \mathrm{~h}$ period, after which haemofiltration in postdilution mode can continue according to the clinical conditions if needed for renal support.

\section{Proteic profiles in extracorporeal filtration adsorption systems}

The high-throughput technique Surface Enhanced Laser Desorption/Ionization Time-ofFlight Mass Spectrometry (SELDI-ToFMS) is powerfully used to analyze the protein content of various biological samples [37]. In particular it helps to identifies the types of molecules that could cross the convective membranes and to quantify their relative adsorption onto the resin bed.

The extraction capability could be evaluated as regard to specific pro-inflammatory proteins such as Tumor Necrosis Factor- $\alpha$ (TNF- $\alpha$ ), Interleukin 6 (IL-6), $\alpha$-1-acid glycoprotein [AAG] and Albumin,.

Three different permeability membrane, Polyphenylene High Flux (pHF), polyphenylene Super High-Flux (pSHF) and Synclear 0.2 (Synclear 0.2), whose sieving coefficient are shown in Figure 5, have been investigated and analyzed for their permeability [38].

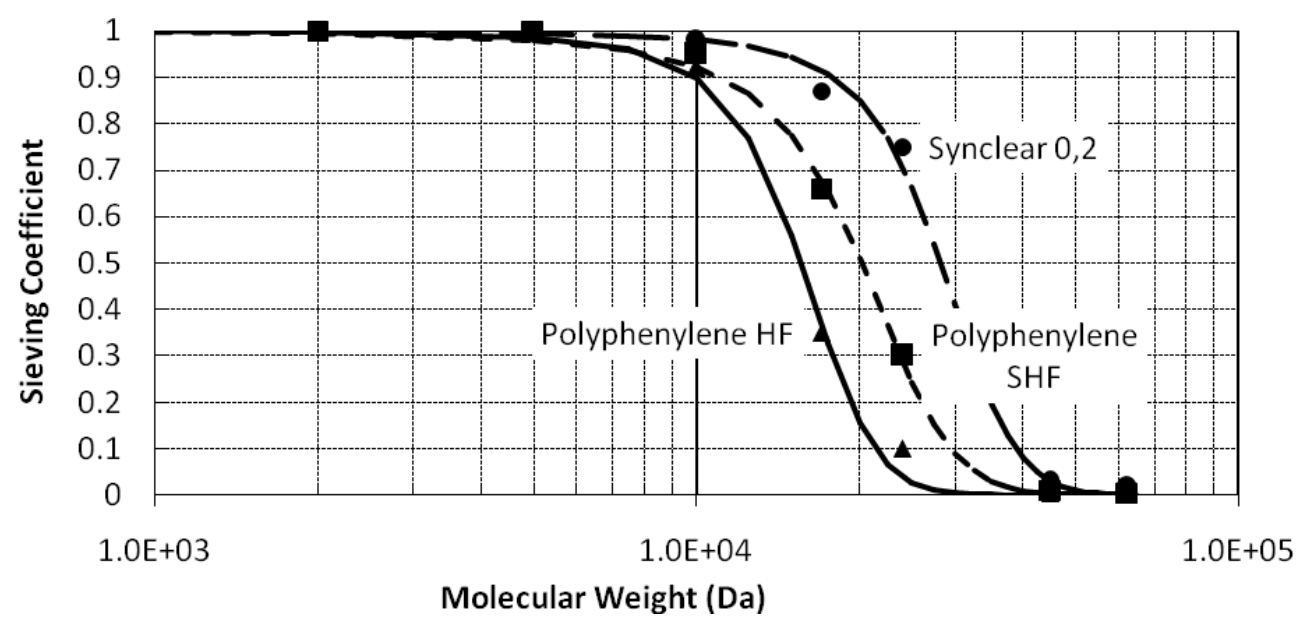

Figure 5. Sieving Coefficient calculated using in vivo data for the membrane Polyphenylene HF, Polyphenylene SHF, Synclear 02. 
Through nephelometric quantification, (see Figure 6), it is clearly remarkable the high permeability of Synclear 0.2 membrane as shown by the different quantity of high molecular weight molecules which are present in the $u f$.

In particular, it is worth to note, that the membrane with higher pores dimension (Synclear 0,2 ) allows passage of a higher percentage of albumin with respect to the membrane with lowest pore size (pHF). Much more interesting is the extraction rate of a molecule as $\alpha-1$ acid glycoprotein despite it has a molecular weight lower than albumin (41-43 kDa vs 66.5 $\mathrm{kDa}$ ). The different behaviour of such a peptide can be explained by introducing the concept of Stokes radii of a protein, its glycosylation and its subproducts.

The Stokes radius or hydrodynamic radius, is the radius of a hard sphere that diffuses at the same rate as the molecule. This is subtly different to the effective radius of a hydrated molecule in solution. The behaviour of this sphere includes hydration and shape effects. Since most molecules are not perfectly spherical, the Stokes radius is smaller than the effective radius (or the rotational radius). A more extended molecule will have a larger Stokes radius compared to a more compact molecule of the same molecular weight. [39]. For an unglycosylated polypeptide, a value to $+\mathrm{g} / \mathrm{mol}$ can be obtained from sequence information or from mass spectrometry. A similar precision cannot be obtained for glycosylated proteins because of polydispersity deriving from the variability of a cell's glycosylation process. Many proteins -and glycoproteins- contain more than one non-covalently linked protein chain, particularly at higher concentrations, and important roles of hydrodynamic methods for mass analysis in protein chemistry are to give the molar mass of the "intact" or "quaternary" structure and to provide an idea of the strength of binding of these non-covalent entities through measurement of association constants [40].

Finally, Table 1 compares the percentage extraction of the different solutes according to molecular weight and the Stokes radius.

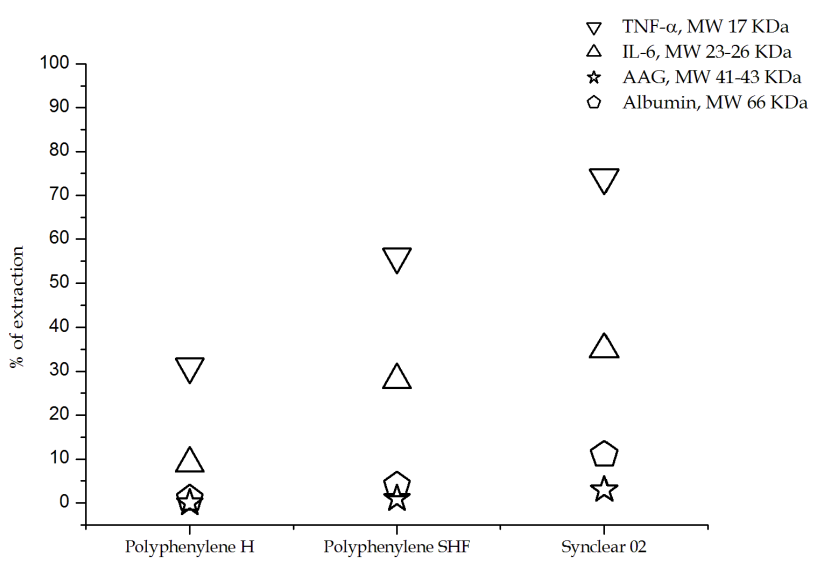

Figure 6. Extraction capability of three different membranes of four molecules. 


\begin{tabular}{lcccc}
\hline & TNF-a & IL-6 & Albumin & AAG \\
\hline Molecular weight & monomer 17 KDa, trimer 51 KDa & $23-26 \mathrm{KDa}$ & $41-41 \mathrm{KDa}$ & $66,5 \mathrm{KDa}$ \\
\hline Stokes radii & monomer $1.9 \mathrm{~nm} /$ trimer 2,3 nm & $2 \mathrm{~nm}$ & $3,5 \mathrm{~nm}$ & $3,5 \mathrm{~nm}$ \\
\hline Polyphenylene H & $31 \%$ & $9 \%$ & $1 \%$ & $0 \%$ \\
\hline Polyphenylene SHF & $56 \%$ & $28 \%$ & $4 \%$ & $1 \%$ \\
\hline Synclear 02 & $74 \%$ & $35 \%$ & $11 \%$ & $3 \%$ \\
\hline
\end{tabular}

Table 1. Differences between molecular weight and Stokes radii of TNF-alpha, IL-6, AAG and Albumin. Stokes radii come from literature data: [41-44]. Extraction percentage of different molecules with different membranes.

\section{Clinical experiences with HFR}

Several studies have been published since the first introduction of filtration-adsorption therapies on the late 80 's. Many of them showed that this technique is particularly suited for chronic patients at major risk of inflammation, malnutrition and with cardiovascular function impairment, such as diabetics, elderly, with high C-reactive protein (CRP) levels.

Table 2 shows the results observed in the main clinical trials comparing HFR against or standard HD or convective technique such as on-line HDF (OL-HDF). Most of the authors reported a significant reduction of pre-dialysis levels of $\beta 2$-microglobulin, particularly marked when comparing the time pattern against standard HD. For instance Kim et al. found out a reduction of pre-dialysis plasma levels from 37.7 to $28.3 \mathrm{mg} / \mathrm{L}$ when patients were treated with HFR. Similar results were also observed from Bolasco et al (from 28.9 \pm 8.9 to $22.9 \pm 6.7 \mathrm{mg} / \mathrm{L}, \mathrm{p}=0.008$ ). Panichi et al did not find any significant reduction of the pre-dialysis $\beta 2$-microglobulin over the time but the results were similar to those obtained with OL-HDF.

Pre-dialysis IL-6 significantly reduced over the time as shown by Panichi et al from $14.8 \pm 6.5$ to $10.1 \pm 3.2 \mathrm{pg} / \mathrm{mL}$ and by Bolasco et al from $21.8 \pm 20.4$ to $18.9 \pm 22.2 \mathrm{pg} / \mathrm{mL}$. On the contrary Kim et al found out an increase of IL-6 even though the patients plasma levels were extremely low (1.69 to $2.48 \mathrm{pg} / \mathrm{mL}$ ).

The results about CRP are in accordance to those on IL-6. In fact, CRP decreased by $30 \%$ to $50 \%$ over time respect to conventional HD. Similar results were obtained by Panichi in OLHDF and the best results have been seen when patients presented high CRP plasma levels at the baseline.

It must be underlined that pre-dialysis albumin plasma levels did not changed significantly in all the studies reported (on average nearly $3.6 \mathrm{~g} / \mathrm{dL}$ ) even though Panichi reported a pre- 
albumin levels increase more pronounced in HFR than in OL-HDF (from $30.5 \pm 3.5$ to $34.0 \pm 3.9$ $\mathrm{mg} / \mathrm{dL}$ in HFR vs $30.6 \pm 3.9$ to $32.3 \pm 3.5 \mathrm{mg} / \mathrm{dL}$ in OL-HDF). This result can be partly explained by the use of a sterile apyrogen substitution fluid (which is true for OL-HDF and particularly for HFR where the substitution fluid is regenerated by patient $u f$ ) and by the lower removal of essential and branched chain aa typical of HFR. In fact, as already mentioned, in addition to a good removal of uremic toxins and reduction of inflammation of the molecules, the HFR is also characterized by a considerable saving of aa and vitamins. Hemodialysis high flux and OL-HDF are associated with a depletion nearly of $25-30 \%$ of the aa concentration from the beginning of the dialysis session, which quantifies in a loss of about 5-10 g/treatment [7, 50-52].

Ragazzoni et al. [53] have firstly shown that HFR is associated with a significant saving of total aa (essential and branched chain), in comparison with OL- HDF. In a pilot study, 11 patients in conventional HD were randomized to HFR or OL-HDF, and the overall aa removal measured as pre to post-dialysis plasma levels were from $3122 \pm 578 \mu \mathrm{mol} / \mathrm{L}$ to $2395 \pm$ 493in HFR and from $3030 \pm 578$ to $1852 \pm 302$ in post-dialysis respectively.

Borrelli [48] confirmed these results by comparing the HFR with acetate free biofiltration (AFB). In particular, the 48 patients recruited (24 in HFR and 24 in AFB), were observed in a single session as regard the AA loss. The authors reported a depletion of plasma total aa levels from $3176 \pm 722$ to $3044 \pm 687 \mu \mathrm{mol} / \mathrm{L}$ in HFR more pronounced than in AFB from $3399 \pm 621$ to $2551 \pm 428 \mu \mathrm{mol} / \mathrm{L}(\mathrm{p}<0.01)$.

Morosetti M. [58] conducted a pilot study of patients treated with HFR and on-line HDF, measuring plasma levels of vitamin $C$ at the beginning, the end of treatment and in the uf in pre-and post-cartridge. The results have documented that, in HFR, levels of vitamin $C$ in the ultrafiltrate are lower than those detected in plasma, a phenomenon due to the partial oxidation of vitamin during the convection (removal of other species anti-oxidants such as proteins), but at the same time has been shown that the vitamin C contained in the uf is not adsorbed by the HFR cartridge and therefore is re-infused to the patient. Furthermore, the authors have demonstrated that plasma levels of vitamin $\mathrm{C}$, are higher in patients treated with HFR compared to those with on-line HDF

Calò et al. [55] recently studied the plasma levels of inflammation and oxidative stress markers, and the long-term changes in mononuclear cell protein expression of heme-oxygenase- 1 (HO-1) in a prospective longitudinal study trial comparing HFR versus standard HD. Patients in HD were recruited and assessed at the baseline and then they were treated for one year in HFR. Change of oxidized low-density lipoprotein(OxLDL) was significantly lower after 12 months on HFR compared with baseline: $475.4 \pm 110.8 \mathrm{ng} / \mathrm{mL}$ (time zero) versus $393.1 \pm 101.9 \mathrm{ng} / \mathrm{mL}$ (12 months), $\mathrm{p}<0.04$. Moreover, during treatment with HFR the protein expression of HO- 1 over time increased $(\mathrm{p}<0.00001)$ and it approached the statistical significance versus time zero at six months $(0.27 \pm 0.10$ vs. $0.17 \pm 0.11, \mathrm{P}=0.0527)$ and became significantly different from time zero at $9(0.48 \pm 0.20$, p < 0.043) and 12 months $(0.59 \pm 0.32$, $\mathrm{p}<$ 0.004). This result is accompanied by the lack of any change of inducible Nitric Oxide Synthase (iNOS) protein expression over time $(1.02 \pm 0.39$ and $1.06 \pm 0.42$ from 0 to 12 months, respectively, $\mathrm{p}=\mathrm{ns}$ ). 


\begin{tabular}{|c|c|c|c|c|}
\hline Author & Patients & Study Design & Major Results on HFR & $p$ \\
\hline $\begin{array}{l}\text { Panichi, } \\
2006 \\
{[45]}\end{array}$ & $\begin{array}{l}\text { Unselected } \\
\qquad \mathrm{n}=25\end{array}$ & $\begin{array}{l}\text { Prospective randomized } \\
\quad \text { cross-over trial } \\
\text { OL-HDF(4ms) - HFR (4ms) } \\
\text { HFR(4ms) - OL-HDF(4ms) }\end{array}$ & $\begin{array}{l}\beta 2 \text {-microglobulin no change in HFR while } \\
\text { decreased by } 7 \% \text { in OL-HDF } \\
\text { IL- } 6 \text { reduction by } 32 \% \text { in HFR vs } 21 \% \text { in OL-HDF } \\
\text { (significant vs baseline) } \\
\text { CRP reduction by } 30 \% \text { in HFR vs } 38 \% \text { in OL- } \\
\text { HDF(significant vs baseline) } \\
\text { No change in albumin }(3.7 \pm 0.3 \mathrm{~g} / \mathrm{dl} \text { ) } \\
\text { Prealbumin increase by } 11.5 \text { in HFR vs } 5 \% \text { in OL- } \\
\text { HDF }\end{array}$ & $\begin{array}{c}\text { ns } \\
<0.02 \\
<0.05 \\
\text { ns } \\
\text { ns }\end{array}$ \\
\hline $\begin{array}{l}\text { Bolasco, } \\
2006 \\
{[46]}\end{array}$ & $\begin{array}{c}\text { No severe } \\
\text { cirrosis, no } \\
\text { heart failure, no } \\
\text { neoplasm or } \\
\text { chronic } \\
\text { inflammation } \\
n=44\end{array}$ & $\begin{array}{l}\text { Longitudinal } \\
\text { HD (3ms) - HFR (6ms) }\end{array}$ & $\begin{array}{l}\text { B2-microglobulin decrease by } 21 \% \\
\text { CRP drecrease by } 50 \% \\
\text { PTH no changes (on average } 318 \mathrm{pg} / \mathrm{mL} \text { ) } \\
\text { Phospates non change (on average } 5 \mathrm{pg} / \mathrm{mL} \text { ) }\end{array}$ & $\begin{array}{c}0.022 \\
0.02 \\
\text { ns } \\
\text { ns }\end{array}$ \\
\hline $\begin{array}{l}\text { Kim, } \\
2009 \\
{[47]}\end{array}$ & $\begin{array}{l}\text { Unselected } \\
\qquad \mathrm{n}=11\end{array}$ & $\begin{array}{c}\text { Longitudinal study } \\
\mathrm{BHD}(12 \mathrm{wks})-\mathrm{HFR}(12 \mathrm{wks})\end{array}$ & $\begin{array}{l}72 \% \text { reduction of plasma level of leptin } \\
67 \% \text { reduction of adiponectin } \\
\text { No change of IL- } 6 \\
72 \% \text { reduction of plasma level of } \beta 2 \text { - } \\
\text { microglobulin }\end{array}$ & $\begin{array}{c}0.014 \\
0.001 \\
\text { ns } \\
0.002\end{array}$ \\
\hline $\begin{array}{l}\text { Borrelli, } \\
2010 \\
{[48]}\end{array}$ & $\begin{array}{c}\text { No severe } \\
\text { cirrosis, heart } \\
\text { failure, } \\
\text { neoplasm } \\
\text { chronic } \\
\text { inflammation } \\
n=48\end{array}$ & $\begin{array}{l}\text { Observational matched } \\
\text { case-control study } \\
\text { HFR(1s) vs AFB(1s) }\end{array}$ & $\begin{array}{l}17 \% \text { less post-dialysis level of total AA in AFB } \\
\text { than HFR } \\
20 \% \text { less post-dialysis level of essential AA in } \\
\text { AFB than HFR }\end{array}$ & $\begin{array}{c}0.0001 \\
<0.000 \\
1\end{array}$ \\
\hline $\begin{array}{l}\text { Bolasco, } \\
2011 \\
{[49]}\end{array}$ & $\begin{array}{l}\text { Patient with no } \\
\text { chronic or acute } \\
\text { recurrent } \\
\text { inflammation } \\
n=38\end{array}$ & $\begin{array}{l}\text { Prospective randomized } \\
\text { cross-over } \\
\text { AF HFR(3ms) - HFR(3ms) - } \\
\text { AF HFR(3ms) }\end{array}$ & $\begin{array}{l}25 \% \text { reduction of pre-dialysis level of } \beta 2 \text { - } \\
\text { microglobulin } \\
\text { IL- } 6 \text { reduction by } 13 \% \text { vs baseline HD } \\
\text { CRP increase by } 40 \% \text { vs baseline HD } \\
7 \% \text { increase predialysis level Hgb } \\
18 \% \text { reduction of ESA consumption } \\
\text { No change in cytokine preedialysis level } \\
\text { No change in pre-dialysis serum albumin } \\
\text { No change in vitamin supplementation }\end{array}$ & $\begin{array}{c}0.002 \\
<0.04 \\
n s \\
<0.04 \\
\text { ns } \\
\text { ns } \\
\text { ns } \\
\text { ns }\end{array}$ \\
\hline
\end{tabular}

Legend: $A F=A c e t a t e$ Free, $A A=A m i n o A c i d s, A F B=A c e t a t e$ Free Biofiltration, OL-HDF=On Line Hemodiafltration, $\mathrm{ms}=$ months, $\mathrm{s}=$ session, $\mathrm{wks}=$ weeks, $\mathrm{ns}=$ not significant, $C R P=C$-Reactive Protein.

Table 2. Summary of clinical trials HFR in the last six years comparing inflammatory parameters and nutritional makers 
Splendiani et al. [56] have shown that the styrenic resin HFR cartridge is able to adsorb significant amounts of homocysteine without simultaneous adsorption of vit. B12 and folate: this suggests an important mechanism for reducing cardiovascular risk. Cardiac troponin (cTnT) is a sensitive marker of cardiac hypertrophy and myocardial injury and correlates with left ventricular mass. There is evidence that the cTnT plasma concentration increases in chronic uremic patients in renal replacement therapies even without signs of heart disease $[57,58]$ and that cTnT is an independent predictor of cardiovascular events. De Filippi et al. [59] reported that cTnT can be elevated in 30\% to $75 \%$ of uremic patients on hemodialysis, and that even small increases are associated with an increased likelihood of coronary heart disease. Lippi et al. [60] showed that variations of cTnT level after dialysis can be linked to blood hemoconcentration and membranes type. Sommerer at al. [61] reported the existence of a significant correlation between cTnT levels and non-native arteriovenous fistulae (implants and catheters), probably due to a state of chronic inflammation often associated with this type of vascular access.

Even though the recent scientific literature generally reports a diminished impact on inflammation and hyper-catabolism induced by extracorporeal dialysis [62] (maybe due to different types of membranes [63]), a further optimization of the various methods HDF must take into account also the buffer used in dialysis (Dialysis Solution DS) and reinfusion fluids. The use of large amounts of on line reinfusion fluid (pre-, post- or pre/post-dilution) exposes the patient to a risk of direct toxic effects or fluid hemo-compatibility with negative clinical consequences. It 's well known that accelerated atherosclerosis is the main risk factor for morbidity and mortality for dialyzed patients: in addition to traditional risk factors, some others play a key role, such as formation of non-enzymatic glycation products, hyper-homocysteinemia, alterations in calcium-phosphorus balance, hemo-incompatibility reactions. All this is due, not only to the dialysis membranes contact, but can be activated by components of the DS or substitution fluids.

Bolasco et al. [49] studied 25 patients in a cross-over longitudinal study. Patients were recruited and studied in a run-in period of three months in standard HD and they were subsequently treated with standard HFR and acetate free (AF) DS (Lympha ${ }^{\circledR}$ ), each period lasting three months. At the beginning and at the end of each period, blood samples were taken to analyse cTnT plasma levels while blood pressure and heart rate were recorded in all the sessions. The results showed a significant decrease in CTnT from standard HD, to HFR AF at the end of first period (from $1.32 \pm 0.35$ to $1.12 \pm 0.31 \mathrm{ng} / \mathrm{mL}, \mathrm{p}<0.05$ ), a subsequent rise in HFR with DS containing acetate (from $1.12 \pm 0.31$ to $1.28 \pm 0.37 \mathrm{ng} / \mathrm{mL}, \mathrm{p}=<0.05$ ) and a further decline (although not statistically significant) from $1.28 \pm 0.37$ to $1.21 \pm 0.35 \mathrm{ng} / \mathrm{mL}$ in the last period of HFR AF. It was observed a significant systolic and diastolic pressure drop accompanied by a compensatory increase in heart rate during the sessions in standard HFR while arterial blood pressure did not significantly changed in HFR AF. No significant differences of acid-base recovery were observed in the two therapies.

Bolasco et al. [64] studied 16 patients, in a comparison of HFR with conventional HD, with regard erythropoiesis And erythropoiesis stimulating agents (ESAs) requirement. They demonstrated a statistically significant increase of $\mathrm{Hb}$ levels in HFR vs HD (from 11.22 to 
$11.66 \mathrm{~g} / \mathrm{dL}, \mathrm{p}<0.05)$, while for ESAs has been a simultaneous significant decrease from 29,188 to $16,750 \mathrm{IU} / \mathrm{month}(\mathrm{p}=0.01$ ). The data showed that the HFR itself is able to determine an improvement of erythropoiesis.

Based on this study, the HFR seems therefore to be an HDF technique that can positively affect the level of $\mathrm{Hb}$ and the needs of ESAs. This favourable effect seems to be independent from the dialysis dose $(\mathrm{Kt} / \mathrm{V})$, the replacement fluid volume, and the presence or absence of acetate in the DS. This result could be attributed to a saving of useful substances such as aa and vitamins, and the lack of depletion of factors inhibiting erythropoiesis [60].

It must be pointed out that the reinfusion of the same closed-loop patient plasma water guarantees undoubtedly sterility and pyrogenicity that is not always assured in OL-HDF, then reducing the effects of micro-inflammation. In a study involving 166 patients, Axelsson et al. [65] have demonstrated, that there is a significant correlation between the indices of sensitivity to ESAs and levels of CRP and IL-6. Moreover, with a multivariate stepwise regression model they can concluded that ferritin (log), PTH, leptin (log), IL-6 (log)) are significantly associated with the ratio of $\mathrm{ESAs} / \mathrm{Hb}$.

The association between purity of dialysate solution and substitution fluid and ESA consumption or $\mathrm{Hb}$ levels in hemodialysis patients have shown that the ESA dose increases linearly as the plasma levels of IL-6. Patients in whom ultrapure dialysis fluid was used required less epoetin than those in whom standard dialysis fluid was used $(64 \pm 22$ vs $92 \pm 12$ $\mathrm{UI} / \mathrm{Kg} /$ week, $\mathrm{p}<0.05$ ) [66].

Recently, Testa et al. [67] have published positive clinical results on the use of HFR for the removal of serum free light chains (Immunoglobulin Free Light Chains - FLCs). The FLCs are divided into two major classes $\kappa$ and $\lambda$ depending on the aa sequence in the constant portion of the polypeptide. Light chains $\mathrm{k}$ are usually monomers of the weight of $22 \mathrm{kD}$, those $\lambda$ dimers of the weight of $44 \mathrm{kD}$. The production of light chains by plasma cells in the bone marrow is around $500 \mathrm{mg} /$ day. They have a half-life of between two and six hours and are usually filtered and subsequently reabsorbed in the proximal tubule. It 'clear that the concentration of FLCs increases in two situations: increase in production (gammopathies) or reduced clearance, such as in renal failure. There is a direct correlation between serum creatinine and FLCs, and the increase of these units represents a reliable measurement of the progression of renal failure.

The highest rates of FLCs are typical of the uremic patients on hemodialysis, and this shows how the current methods of purification will not be able to offer an adequate clearance of these molecules, defined as true uremic toxins. By contrast, Hutchison et al. [68] have described an alternative strategy of HD intensive filters with membranes with high permeability (Poliariletersulfone with a cut-off of $45 \mathrm{kD}$ ), capable of removing significantly FLCs in excess, method, however, associated with an important loss of albumin of 20-40 g/session.

Testa et al. [67] have studied two different groups of patients treated with HFR: one with production of polyclonal light chains, the other with monoclonal antibodies; the results showed a significant reduction of FLCs in both groups (31\% and $34 \%$ reduction rate of $\kappa$ chains respectively in polyclonal and monoclonal FLCs group; $20 \%$ and $11 \%$ reduction rate 
of $\lambda$ chains again in polyclonal and monoclonal FLCs group). The analysis by $u f$ at cartridge inlet and outlet confirmed the adsorptive capacity of FLCs.

In summary, it should be noted that the HFR can not be greater than the traditional HDF in the field of the elimination of toxic solutes, as the adsorption can not be more effective. The focal point is the best compromise between saving of essential elements and a satisfactory toxins removal in a wide spectrum.

\section{Clinical experience with Couple Plasma-Filtration Adsorption (CPFA)}

First animal experiments with CPFA were done to determine safety and efficacy, as well as whether CPFA could actually play a role in modulating the inflammatory response [69].

Table 3 reports the results obtained in the main clinical trials comparing CPFA with standard treatments. It can be seen that this therapy is in general able to ameliorate the hemodynamic response of septic shock patients highlighted by the general reduction or early interruption of vasopressors and amines in groups treated with CPFA. Moreover, the cytokines plasma levels seem to reduce faster in CPFA than standard treatments.

Ronco and co-workers studied haemodynamic parameters and the ability to restore leucocyte responsiveness in a cross-over trial of septic patients who underwent $10 \mathrm{~h}$ of CPFA followed by $10 \mathrm{~h}$ of continuous venovenoushaemodiafiltration (or vice versa)[70]. They also monitored leucocyte responsiveness to in vitro stimulation by endotoxin. At the beginning of the CPFA treatment the cells were not able to produce appropriate amounts of TNF- $\alpha$, whereas production was restored at the end of treatment. Cell hyporesponsiveness to secondary bacterial challenges is part of an overall immunosuppressive effect seen in septic patients and is frequently associated with worse outcomes [74].

These authors observed a significant improvement in hemodynamics with the use of CPFA compared with hemodiafiltration. They also observed a significant increase in leukocyte responsiveness after CPFA treatment. For these experiments, they monitored spontaneous and endotoxin-stimulated leukocyte TNF- $\alpha$ production after $10 \mathrm{~h}$ of treatment. At the beginning of the treatment, there was a marked leukocyte hyporesponsiveness to endotoxin stimulation (immunosuppression). As the treatment progressed, the responsiveness increased. Further support for the role of CPFA in the restoration of immune responsiveness was observed by incubating pre and post resin plasma with monocytes obtained from healthy donors. The pre-resin plasma at the beginning of treatment had a strong immunosuppressive effect - unless the plasma had first been incubated with monoclonal antibodies to IL-10. In contrast, the post-resin plasma (at the beginning of treatment) produced higher quantities of TNF- $\alpha$ after endotoxin challenge, and nearly normal quantities after 10-hour treatment. One of the interesting observations of this study was the absence of significant changes in circulating plasma levels of IL-10 or TNF- $\alpha$ even though there was almost complete adsorption of these cytokines by the resin cartridge. This suggests that there may still be other factors that are adsorbed by the cartridge that play a role in immunosuppression. 
For this reason, the results presented in this study may be particularly relevant as the end point of the study was restoration of immune responsiveness, rather than a net increase or decrease in specific inflammatory mediators.

Formica and colleagues conducted one of the first trials of CPFA to include septic patients with and without renal insufficiency all of them with a high APACHE II score (24.8 B 5.6) and multiorgan failure. Six of the 10 patients had normal renal function. The authors performed 10 consecutive sessions and observed a net decrease in vasopressor requirement, increased mean arterial pressure, improved pulmonary function and a reduction in C-reactive protein. The patients treated with CPFA had a 70\% survival [71].

Another study by Mariano and colleagues [77] evaluated CPFA in burn and polytrauma patients with septic shock and acute renal failure. Patients were divided into either heparin or citrate anticoagulation based on whether they had a high bleeding risk. The citrate anticoagulation was well tolerated and gave comparable results to the group with heparin anticoagulation. The previous CPFA studies included septic patients with acute renal failure that required renal support.

Recently, Berlot et al. [78] showed in septic shock a case report in which CPFA was able to ameliorate the microcirculation during the session. Sublingual microvascular perfusion was assessed using the orthogonal polarisation spectral imaging technique at three different times: pre-CPFA, at two hours during the treatment and two hours after the end of the session. During CPFA, the number of perfused vessels increased compared with the pre-treatment period, but decreased again after its termination. The author concluded that the elimination of septic mediators during the procedure could account for the observed microvascular perfusion variations.

Further case histories pointed out the effectiveness of CPFA in several other diseases such liver failure [79], Weil's syndrome [80] acute respiratory distress syndrome (ARDS) [81].

Caroleo et al. studied a case of a 70-year-old woman who developed hypoxic hepatitis secondary to cardiogenic shock after cardiac surgery [79]. CPFA was used primarily as an extracorporeal supportive therapy for multiple organ failure (MOF). The authors reported a significant reduction of the plasmatic concentration of conjugated bilirubin, achieving a mean reduction rate (RR) of $53 \%$ during treatment. CPFA proved to be a valid tool for concomitant hemodynamic support and organ replacement therapy.

Moretti and coworkes reported a case of a 27-year-old man with Weil's syndrome accompanied with hypotension, anuria refractory to fluid therapy, ARDS, and hepatic involvement [80]. CPFA was started early after the onset of shock and five treatments were performed. Each session lasted for $10 \mathrm{~h}$ with $14 \mathrm{~h}$ interval. Weaning from vasopressors was achieved during the second course of CPFA, while weaning from ventilation was achieved after 6 days.

Lucisano et al reporteda case of a 43-year-old male who developed ARDS secondary to pneumonia and acute kidney injury, whose clinical conditions rapidly improved after early CPFA therapy [81]. CPFA was performed for 6-8 h (daily, for three consecutive days). 
Twenty-four hours after the first CPFA session CPAP was withdrawn. After 4 days, the oxygen saturation achieved $97 \%$ without ventilation. During the 3 days in which CPFA treatments were carried out, serum levels of pro-inflammatory cytokines, procalcitonin and CRP decreased progressively as well as APACHE II which achieved a score of 9 five days after the first CPFA session.

\begin{tabular}{|c|c|c|c|c|}
\hline Author & Patients & Study Design & Major Results & $P$ \\
\hline Ronco & Septic pts & Prospective Randomized & Improvement of hemodynamic & \\
\hline 2000 & $\mathrm{~N}=$ unknown & Controlled Trial & response & \\
\hline \multirow[t]{2}{*}[70]{} & & CPFA - CVVH & Reduction of norepinephrine dose & \\
\hline & & CVVH - CPFA & & \\
\hline Formica & Septic shock pts & Prospective Longitudinal & Improvement of MAP & $<0.001$ \\
\hline 2003 & $\mathrm{~N}=12$ & CPFA & Improvement of Cardiac Index & $<0.001$ \\
\hline \multirow[t]{6}{*}{ [71] } & & & Increase of SystVasc Res Index & $<0.001$ \\
\hline & & & Improvement of $\mathrm{PaO} 2 / \mathrm{FiO} 2$ & $<0.001$ \\
\hline & & & No change extracvascular lung water & Ns \\
\hline & & & intra-thoracic blood index & Ns \\
\hline & & & Survival @ 28 days 90\%, @90 days & \\
\hline & & & $70 \%$ & \\
\hline Ronco & Septic shock pts & Prospective pilot & Increase of MAP by 11.8 vs $5.5 \mathrm{mmHg}$ & 0.001 \\
\hline 2002 & $N=10$ & CPFA (10h) - CVVHDF (10h) & Reduction of norepinephrine 0.08 vs & 0.003 \\
\hline$[72]$ & & CVVHDF (10h) - CPFA (10h) & $0.0049 \mathrm{ug} / \mathrm{Kg} / \mathrm{min}$ & \\
\hline Lentini & Septic shock, AKI & Prospective Randomized & No change MAP & 0.29 \\
\hline \multirow[t]{3}{*}{2009} & $\mathrm{~N}=8$ & Controlled Trial & No change Norepinephrine & 0.18 \\
\hline & & HVHF-CVVH-CPFA-CVVH & No change Vasopressor & 0.22 \\
\hline & & CPFA-CVVH-HVHF-CVVH & No change $\mathrm{PaO} 2 / \mathrm{FiO}_{2}$ & 0.08 \\
\hline Mao & Septic shock, MOF & Prospective Randomized & Increase MAP $120.75 \pm 20$ vs $115.3 \pm 18.5$ & $<0.05$ \\
\hline 2011 & $\mathrm{~N}=7$ & Controlled Trial & $\mathrm{mmHg}$ & $<0.05$ \\
\hline \multirow[t]{2}{*}[74]{} & & CPFA (10h) - HVHF (10h) & $\mathrm{paO} 2 / \mathrm{FiO} 2297.3 \pm 204$ vs $265.45 \pm 173.7$ & \\
\hline & & HVHF (10h) - CPFA (10h) & reduction of Cytokines plasma levels & \\
\hline $\mathrm{HuD}$ & Septic patients or & Prospective Randomized & TNFa $(\mathrm{pg} / \mathrm{mL}): 178 \pm 58 \rightarrow 186.9 \pm 55.1 \mathrm{in}$ & $<0.01$ \\
\hline 2012 & MODS & Controlled Trial & HVHF; $229.8 \pm 44.2 \rightarrow 151.8 \pm 29.4$ in & $<0.01$ \\
\hline \multirow[t]{4}{*}[75]{} & $\mathrm{N}=14$ & CPFA & CPFA & \\
\hline & & HVHF & Intercellular adhesion molecule-1 (ng/ & \\
\hline & & & $\mathrm{mL}): 708.1 \pm 98.3$ to $675.6 \pm 44.4$ in HVHF & \\
\hline & & & vs $798.1 \pm 134.1$ to $347.6 \pm 181.5$ & \\
\hline
\end{tabular}

Legend: $\mathrm{CVVH}=$ Continuous Venous-Venous Hemofiltration; HVHF=High Volume HemoFiltration; MAP=Mean Arterial Pressure; MODS= Mutli Organ Distress Syndrome.

Table 3. Summary of the main clinical CPFA trials. 


\section{Conclusions}

Although extracorporeal treatments have shown several developments over the years in the attempt to achieve better results in terms of survival both in acute and chronic patients, nevertheless they still remain poorly selective and with many limitations linked to the loss of nobles substances.

Filtration-adsorption architectures seems to be viable forms of extracorporeal blood purification systems which can enhance the capability to remove molecules in a wide range of molecular weight spectrum with the advantage of retaining molecules essential to the organs and subject life.

HDF has bee proven to obtain better clinical results in chronic dialysis population, even though renal replacement therapies still suffer from drawbacks related to inflammation, oxidative stress, morbidity and cardiovascular associated diseases. Diabetes, hypertension and age, often translate into clinical frailty and poor quality of life, often closer to survival than to cope with the disease. All these factors are extremely important in the choice of the convective therapy to adopt. HFR seems to combine a high removal of uremic toxins thus lowering the micro-inflammation status which can bring to benefits especially in cardiac compromised.

Further developments of this architecture could come from the use of super high-flux membranes with cut-off values much higher than the albumin limit and/or from the discovery of new adsorbent resins even more selective to specific molecules responsible for particular diseases.

In the meanwhile, we can take advantages of the clinical results gathered so far which can address the HFR to malnourished and inflamed patients and CPFA to septic ones.

Further studies are advocated to understand the potential of such architectures on high-end points like survival of both acute and chronic population as well as quality of life.

\section{Author details}

Fabio Grandi ${ }^{1}$, Piergiorgio Bolasco ${ }^{2}$, Giuseppe Palladino ${ }^{1}$, Luisa Sereni ${ }^{1}$, Marialuisa Caiazzo ${ }^{3}$, Mauro Atti ${ }^{1}$ and Paolo Maria Ghezzi ${ }^{1}$

1 Bellco S.r.l., Mirandola, Italy

2 Territorial Department of Nephrology and Dialysis, ASL Cagliari, Italy

3 Laboratory Diagnostics and Forensic Medicine University of Modena and Reggio Emilia, Italy 


\section{References}

[1] Andrade, J., Hlady, V., Plasma, protein., adsorption, the., big, twelve., Ann, Ny., \& Acad, Sci. (1987). 516, 158-172.

[2] Lagsdorf LJ, Zydney AL, Effect of blood contact on the transport properties of hemodialysis membranes: a two-layers model, Blood Purif,. (1994). 12, 292-307.

[3] Lutz, H., Ultrafiltration, fundamentals., engineering, in., Drioli, , Giorno, ., Ed., , Comprehensive, membrane., science, , \& engineering, Elsevier. (2010). 2.

[4] Rockel, A., Hertel, J., Fiegel, P., et al., Permeability, , secondary, membrane., formation, of. a., high, flux., polysulfonehemofilter, , \& Kidney, International. (1986). 30, 429-32.

[5] Kunitomo, T., Lowrie, E. G., Kumazawa, S., et al. Controlled ultrafiltration with hemodialysis: analysis of coupling between convective and diffusive mass tansfer in a new HD-uf system, Trans Am SocArtif Intern Organs (1977). , 23, 234-43.

[6] Leber, H. W., Wizemann, V., Goubeaud, G., et al., Simultaneous, hemodialysis/hemofiltration., an, effective., alternative, to., hemofiltration, , conventional, hemodialysis., in, the., treatment, of., uremic, patients., \& Clin, . ClinNephrol (1978). , 9, 115-21.

[7] Navarro, J. F., Marcen, R., Teruel, J. L., et al. Effect of different membranes on aminoacid losses during hemodialysis. Nephrol Dial Transplant (1998).

[8] Sargent, J. A., Gotch, F. A., Principle, , biophysics, of., dialysis, Jacobs. C., Kjellstrand, C. M., Koch, K. M., Winchester, J. F., 4th, Ed., Replacement, of., renal, function., \& by, dialysis. (1996). 34-102.

[9] Michaels AS, Operating parameters and performance criteria for hemodialyzers and other membrane-separation devices, Trans Am SocArtifInt Organs,. (1966). 12, 387-392.

[10] Ghezzi, P. M., Frigato, G., Fantini, G. F., et al. Theoretical model and first clinical results of the Paired Filtration Dialysis (PFD),. Life Support Syst (1983). suppl 1) , 271 EOF-4 EOF.

[11] Botella, J., Ghezzi, P. M., Sanz-Moreno, C., et al. Multicentric study on paired filtration dialysis as a short efficient dialysis technique. Nephrol. Dial Transplant, (1991). , $6,715-721$.

[12] Gurland, H. J., Davison, A. M., Bonomini, V., et al. Definitions and terminology in biocompatibility. Nephrol Dial Transplant, (1994). Suppl 2), 4-10., 4 EOF.

[13] Winchester, JF: Hemoperfusion, in Maher JF, Dordrecht, Kluwer Academic Publishers ( $\left.3^{\text {rd }} \mathrm{ed}\right)$, Replacement of Renal Function by Dialysis. (1989). 439-459.

[14] Muirhead, , Reid, A. F., Resin, artificial., kidney, J., \& Lab, Clin. ClinMed,(1948). , 33, 841-844. 
[15] Yatzidis, H. A., convenient, hemoperfusion., micro-apparatus, over., charcoal, for., the, treatment., of, endogenous., exogenous, intoxication., Proc, Eur., Dial, Transplant., \& Assoc, . (1964). 1, 83-86.

[16] Chang, TMS: Semipermeable aqueous microcapsules (artificial cells): With emphasis on experiments in an extracorporeal shunt system.Trans Am SocArtif Intern Organs, (1966). , 12, 13-19.

[17] Chang, T. M. S., Chirito, E., Barre, B., Cole, C., Hewish, M., Clinical, evaluation., of, chronic., intermittent, , short, term., hemoperfusion, in., patients, with., chronic, renal., failure, using., semipermeable, microcapsules., (artificial, cells., formed, from., membrane, coated., \& activated, charcoal. Trans Am SocArtif Intern Organs, (1971). , $17,246-252$.

[18] Gordon, A., Greenbaum, Marantz. L. B., Mc Arthur, Maxwell. M. H. A., sorbentbased, low., recirculating, dialysate., \& system, . Trans Am SocArtifInt Organs, (1969). , 15, 347-352.

[19] Branger, B., Ramperez, P., Marigliano, N., et al., Aluminium, transfer., in, bicarbonate., dialysis, using. a., sorbent, regenerative., system, an., in, vitro., \& study, Proc. E. D. T. A. (1980). 17, 213-218.

[20] Randerson, D. H., Gurland, H. J., Schmidt, B., et al. Sorbent membrane dialysis in uremia. ContribNephrol, (1982). , 29, 53-64.

[21] Shaldon, S., Beau, M. C., Claret, G., et al. Haemofiltration with sorbent regeneration of ultrafiltrate: First clinical experience in end stage renal disease. ProcEur Dial Transplant Assoc, (1978). , 15, 220-227.

[22] Mion, C., Branger, B., Issautier, R., et al. Dialysis fracturing osteomalacia without hyperparathyroidism in patients treated with $\mathrm{HCO} 3$ rinsed Redy cartridge. Trans Am SocArtif Intern Organs, (1981). , 27, 634-638.

[23] Randerson, D. H., Gurland, H. J., Schmidt, B., et al. Sorbent membrane dialysis in uremia,. Contrib Nephrol, (1982). , 29, 53-64.

[24] Atti, M., Wratten, M. L., Sereni, A., et al. Contact phase activation can occur with certain types of activated carbon. G ItalNefrol. (2004). Suppl 30), S, 62-66.

[25] Wratten, M. L., Sereni, L., Lupotti, M., et al. Optimization of a HFR sorbent cartridge for high molecular weight uremic toxins. G ItalNefrol. (2004). Suppl 30), S, 67-70.

[26] Ghezzi, P. M., Dutto, A., Gervasio, R., Botella, J., Hemodiafiltration, with., the, separate., convection, , diffusion, Paired., filtration, dialysis., \& Contrib, Nephrol. (1989). $69,141-161$.

[27] Botella, J., Ghezzi, P. M., Sanz-Moreno, C., et al. Multicentric study on paired filtration dialysis as a short efficient dialysis technique. Nephrol. Dial Transplant, (1991). , 6, 715-721. 
[28] Aucella, F. Hemodiafiltration with endogenous reinfusion, G ItalNefrol, (2012). S55), SS82., 72.

[29] De Simone, W., De Simone, M., De Simone, A., et al. Aspetti dell'emodiafiltrazione online con rigenerazione e reinfusione dell'ultrafiltrato (HFR). Studio multicentrico. Giorn It Nefrol, (2004). Suppl 30), SS167., 161.

[30] Richter, R., Schulz-Knappe, P., Schrader, M., et al. Composition of the peptide fraction in human blood plasma: Database of circulating human peptides,. J Chromatogr B Biomed SciAppl, (1999). , 726, 25-35.

[31] Lefler DM, Pafford RG, Black NA, et al.Identification of proteins in slow continuous ultrafiltrate by reversed-phase chromatography and proteomics,. J Proteome Res, (2004). , 3, 1254-60.

[32] Weissinger, E. M., Kaiser, T., Meert, N., et al., Proteomics, a., novel, tool., to, unravel., the, patho-physiology., of, uraemia., Nephrol, Dial., \& Transplant, . (2004). 19, 3068-77.

[33] Botella, J., Ghezzi, P. M., Sanz-Moreno, C., Adsorption, in., hemodialysis, Kidney., \& Int, . (2000). SS65., 60.

[34] Ronco, C., Brendolan, A., d'Intini, V., et al. Coupled plasma filtration adsorption: rationale, technical development and early clinical experience,. Blood Purif, (2003).

[35] Winchester, J. F., Kellum, J. A., Ronco, C., et al. Sorbents in acute renal failure and the systemic inflammatory response syndrome. Blood Purif, (2003). , 21, 79-84.

[36] Wratten ML Therapeutic approaches to reduce systemic inflammation in septic-associated neurologic complications European Journal of Anaesthesiology,(2008). Suppl 42), 1-7.

[37] De Bock, M., de Seny, D., Meuwis, M., , A., Chapelle, J., , P., et al., Challenges, for., biomarker, discovery., in, body., fluids-T, using. S. E. L. D. I., \& , O. F. M. S. Journal of biomedicine \& biotechnology (2010).

[38] Caiazzo M., CuoghiA., Monari E., et al. STEPS Study: Superior Therapies for hEmodialysiS. A proteomic approach. Poster at 49 ERA-EDTA 2012 DOI:pso.eu.49era. (2012).

[39] Gert, R., \& Strobl, . (1996). The Physics of Polymers Concepts for Understanding Their Structures and Behavior. Springer-Verlag. 3-54060-768-4

[40] Hardinc, S. H., \& Protein, Hydrodynamic_. H. A. R. D. I. N. G. S. E. (1999). Protein hydrodynamics. In: ALLEN, G., ed., Protein: A Comprehensive Treatise 2. JAI Press Inc, Greenwich, USA. , 271-305.

[41] Kimmel, J. D., Gibson, G. A., Watkins, S. C., Kellum, J. A., Federspiel, W. J. I. L., Adsorption, Dynamics., in, Hemoadsorption., Beads, Studied., Using, Confocal., Laser, Scanning., Microscopy, Journal., of, Biomedical., Materials, Research., Part, B., \& Applied, Biomaterials. (2009). B(2), 390-396. 
[42] Narhi, L.O., Arakawa, T., Dissociation of recombinant tumor necrosis factor- $\alpha$ studied by gel permeation chromatography; Biochem and biopsy Res Communic,. (1978).

[43] Atmeh, R. F., Arafa, I. M., Al-Khateeb, M., Albumin, Aggregates., Hydrodynamic, Shape., Physico-Chemical, Properties., Jordan, Journal., \& of, Chemistry. (2007).

[44] Sviridov, D., Meilinger, B., Drake, S. K., Hoehn, G. T., Hortin, G. L., Coelution, of., other, proteins., with, albumin., during, size-exclusion. H. P. L. C., Implications, for., analysis, of., \& urinary, albumin. (2006). Clinical Chemistry, 389 EOF-97 EOF.

[45] Panichi, V., Manca-Rizza, G., Paoletti, S., et al. Effects on inflammatory and nutritional markers of hemodiafiltration with online regeneration of ultrafiltrate (HFR) vs. online hemodiafiltration: a cross-over randomized multicentre trial, Nephrol Dial Transplant (2006). , 21, 756-62.

[46] Bolasco, P. G., Ghezzi, P. M., Ferrara, R., et al. Effect of on-line hemodiafiltration with endogenous reinfusion (HFR) on the calcium-phosphorus metabolism: medium-term effects,. Int J Artif Organs, (2006). , 29, 1042-52.

[47] Kim, S., Oh, K. H., Chin, H. J., Na, K. Y., et al. Effective removal of leptin via hemodiafiltration with on-line endogenous reinfusion therapy, Clinical Nephrology, (2009).

[48] Borrelli, S., Minutolo, R., De Nicola, L., et al. Intradialytic changes of plasma amino acid levels: effect of hemodiafiltration with endogenous reinfusion versus acetatefree biofiltration. Blood Purif, (2010). , 166 EOF-171 EOF.

[49] Bolasco, P., Ghezzi, P. M., Serra, A., et, al. E., Effects, of., acetate-free, haemodiafiltration. . H. D. F., with, endogenous., reinfusion, . H. F. R., on, cardiac., \& troponin, levels. Sardinian Polycentric Study on Acetate-Free Haemodiafiltration, Nephrol Dial Transplant, (2011).

[50] Ikizler TA, Flakoll PJ, Parker RA, Hakim RM.Amino acid and albumin losses during hemodialysis,. Kidney Int, (1994). , 830 EOF-7 EOF.

[51] Navarro, J. F., Mora, C., Leon, C., et al. Amino acid losses during hemodialysis with polyacrylonitrile membranes: effect of intradialitic amino acid supplementation on plasma amino acid concentrations and nutritional variables in nondiabetic patients. Am J ClinNutr (2000).

[52] Prado de, Negreiros., Nogueira, Maduro. I., Elias, N. M., \& Nonino, Borges. C. B. Total nitrogen and free amino acid losses and protein calorie malnutrition of hemodialysis patients: do they really matter? Nephron Clin Pract, (2007). cc17., 9.

[53] Ragazzoni, E., Carpani, P., Agliata, S., et, al. H. F. R., on-line, H. D. F., valutazione della, perdita., \& aminoacidica, plasmatica. Giorn It Nefrol (2004). suppl 30), 85-90.

[54] Morosetti, M. personal communication 
[55] Calò, L. A., Naso, A., Devis, P. A., et al. Hemodiafiltration with on-line regeneration of ultrafiltrate: effect on Heme-Oxygenase-1 and inducible subunit of Nitric Oxide Synthase and implication for oxidative stress and inflammation.,Artif Org (2010).

[56] Splendiani, G., De Angelis, S., Tullio, T., et al. Selective adsorption of homocysteine using an HFR online technique, Artif Organs (2004). , 28, 592-95.

[57] Deléaval, P., Descombes, E., Magnin, J. L., Rossi, S., \& Chiatto, M. Differences in cardiac troponin I and $\mathrm{T}$ levels measurement in asymptomatic hemodialysis patients with last generation immunoassays, NephrolTher, (2008). , 2, 75-81.

[58] Katerinis, I., Nguyen, Q. W., Magnin, J. L., \& Descombes, E. (2008). Cardiac findings in asymptomatic hemodialysis patients with persistently elevated cardiac troponin levels, Ren Fail. 30, 357-62.

[59] De Filippi, C., Wasserman, S., Rosani, S., Cardiac, troponin. T., C-reactive, protein., for, predicting., progonosis, coronary., atherosclerosis, , cardiomyopathy, in., patients, undergoing., \& long-term, hemodialysis. J. A. M. A. (2003). 290, 353-59.

[60] Lippi, G., Tessitore, N., Montagnana, M., et al. Influence of sampling time and ultrafiltration coefficient of the dialysis membrane on cardiac troponin I and T. ArchPathol Lab Med (2008). , 132, 72-76.

[61] Sommerer, C., Heckele, S., Schwenger, V., et al. Cardiac biomarkers are influenced by dialysis characteristics,. ClinNephrol, (2007). , 68, 392-400.

[62] Peruzzi, L., Camilla, R., Bonaudo, R., Coppo, R., \& Amore, A. Bioincompatibility of acetate even at low concentrations. G ItalNefrol. (2011). , 289 EOF-95 EOF.

[63] Amore, A., Cirina, P., Bonaudo, R., et al., Bicarbonate, dialysis., unlike, acetate-free., biofiltration, triggers., mediators, of., inflammation, , apoptosis, in., endothelial, , smooth, muscle., cells, J., \& Nephrol, . (2006). 57 EOF-64 EOF.

[64] Bolasco, P. G., Ghezzi, P. M., Serra, A., et al. Hemodiafiltration with endogenous reinfusion with and without acetate-free dialysis solutions: effect on ESA requirement. Blood Purif, (2011). , 235 EOF-242 EOF.

[65] Axelsson, J., Quereshi, A. R., Heimburger, O., et al. Body fat mass and serum leptin levels influence epoetin sensitivity in patients with ESRD. Am J Kidney Dis, (2005). , $46,628-34$.

[66] Sitter, T., Bergner, A., Schiffle, H., Dialysis-relate, cytokine., induction, , response, to., recombinant, human., erythropoietin, in., hemodiaysis, patients., Nephrol, Dial., \& Transplant, . (2000). 15, 1207-1211.

[67] Testa, A., Dejoie, T., Lecarrer, D., et al. Reduction of free immunoglobulin light chains using adsorption properties of hemodiafiltration with endogenous reinfusion. Blood Purif, (2010). , 34 EOF-36 EOF. 
[68] Hutchison, Cockwell. P., Reid, S., et al. Efficient removal of immunoglobulin free light chains by hemodialysis for multiple myeloma. J Am Soc Nephrol (2007). ; ., 18, 886-95.

[69] Tetta, C., Gianotti, L., Cavaillon, J. M., et al. Coupled plasma filtration-adsorption in a rabbit model of endotoxic shock,. Crit Care Med, (2000). , 1526 EOF-33 EOF.

[70] Ronco, C., Brendolan, A., Dan, M., et al., Adsorption, in., sepsis, Kidney., \& Int, Suppl. (2000). Aug;76:S, 148-55.

[71] Formica, M., Olivieri, C., Livigni, S., et al. Hemodynamic response to coupled plasmafiltrationadsoprtion in human septic shock, Intensive Care Med, (2003). , 29, 703-708.

[72] Ronco, C., Brendolan, A., Lonnemann, G., et, al. A., pilot, study., of, coupled., plasma, filtration., with, adsorption., in, septic., shock, Crit., \& Care, . (2002). 1250 EOF-5 EOF.

[73] Lentini, P., Cruz, D., Nalesso, F., et, al. A., pilot, study., comparing, pulse., high, volume., hemofiltration, (p. H. V. H. F., coupled, plasma., filtration, adsorption. . C. P. F. A., in, septic., shock, patients. G., \& Ital, Nefrol. (2009).

[74] Mao, H., Yu, S., Yu, X., et al. Effect of coupled plasma filtration adsorption on endothelial cell function in patients with multiple organ dysfunction syndrome. Int J Artif Organs. (2011). , 288 EOF-294 EOF.

[75] Hu, D., Sun, S., Zhu, B., et al. Effects of coupled plasma filtration adsorption on septic patients with multiple organ dysfunction syndrome. Ren Fail. 2012; 34(7), Epub (2012). May 18., 834 EOF-839 EOF.

[76] Ronco, C., Tetta, C., Mariano, F., et al. Interpreting the mechanisms of continuous renal replacement therapy in sepsis: the peak concentration hypothesis. Artif Organs, (2003). , 27, 792-801.

[77] Mariano, F., Tetta, C., Stella, M., et al. Regional Citrate Anticoagulation in Critically Ill Patients treated with Plasma Filtration and Adsorption. Blood Purif, (2004). , 22, 313-9.

[78] Berlot, G., Bianco, N., Tomasini, A., et al. Changes in microvascular blood flow during coupled plasma filtration and adsorption Anaesth Intensive Care, (2011). , 39, 687-689.

[79] Caroleo, S., Rubino, Tropea. F., et al., Coupled, plasma., filtration, adsorption., reduces, serum., bilirubine, in. a., case, of., acute, hypoxic., hepatitis, secondary., to, cardiogenic., shock, Int. J., \& Artif, Organs. (2010).

[80] Moretti, R., Scarrone, S., Pizzi, B., et al. Coupled Plasma Filtration Adsorption in Weil's syndrome: a case report. Minerva Anestesiol, (2011). , 77, 846-849.

[81] Lucisano, G., Capria, M., Matera, G., et al., Coupled, plasma., filtration, adsorption., for, the., treatment, of. a., patient, with., acute, respiratory., distress, syndrome., acute, kidney., injury, a., case, report., Nephrol, Dial., \& Transplant, Plus. (2011). 4, 285-288. 